\title{
Seismic Behavior of Shear Connectors of Steel Vierendeel Sandwich Plate
}

\author{
Lan Jiang, ${ }^{1,2}$ Kejian Ma, ${ }^{1,3}$ Huagang Zhang $\mathbb{D},{ }^{3}$ Qin Wu, ${ }^{3}$ Hongna Lu, ${ }^{3}$ and Qizhu Yang ${ }^{4}$ \\ ${ }^{1}$ Collage of Civil Engineering, Hunan University, Changsha HN 731, China \\ ${ }^{2}$ College of Electrical Engineering \& New Energy, China Three Gorges University, Yichang HB 717, China \\ ${ }^{3}$ Space Structures Research Center, Guizhou University, Guiyang GZ 851, China \\ ${ }^{4}$ College of Urban Construction, Shaoyang University, Shaoyang HN 739, China
}

Correspondence should be addressed to Huagang Zhang; hgzhang@gzu.edu.cn

Received 24 March 2019; Accepted 26 May 2019; Published 12 June 2019

Academic Editor: Alberto Campagnolo

Copyright (c) 2019 Lan Jiang et al. This is an open access article distributed under the Creative Commons Attribution License, which permits unrestricted use, distribution, and reproduction in any medium, provided the original work is properly cited.

\begin{abstract}
As a new type of floor structure, steel vierendeel sandwich plates are widely applied in large-span buildings with multiple storeys. Shear connectors are important stressed members of such plates. To evaluate the seismic performance of the shear connectors, a full-scale test piece in two different connection forms, namely, A and B, is designed and tested under alternating load. Test analysis of the two connection specimens covers the failure modes, hysteresis curves, and main parameters (e.g., bearing capacity, ductility, stiffness degradation, and energy dissipation coefficient). The following results concerning type A connection are obtained: First, it exhibits good ductility and long yielding platform; second, elastoplasticity of steel is fully exerted with it; third, it absorbs and dissipates energy well with strong energy consumption; and fourth, when failure occurs, cracks usually happen in the heat-affected zone of the weld in the core zone. The following conclusions about type B are drawn: first, it has large bearing capacity with high stiffness; also, when failure occurs, the ribbed stiffeners crack and flexion deformity happen.
\end{abstract}

\section{Introduction}

Steel vierendeel floor slab was invented by Ma Kejian et al. in 2002 [1]. In industrial and civil buildings, the size of the column net should be expanded and the thickness of the floor structure and the structural weight should be reduced due to the needs of production processes and functional purposes [2]. Prestressed, steel-concrete composite floor, and combined grid structures are commonly included in largespan floor coverings. Steel vierendeel floor slab is well adapted to these requirements and is a structural form with broad application prospects [1]. Steel vierendeel sandwich plate has the following advantages.

(i) For buildings with large and small spans, the normal depth of steel vierendeel floor slab ranges from span/30 to span/25.

(ii) The space between the top and bottom chords can be threaded to save the layer height (Figure 1).

(iii) The floor slab is light because a hole exists between the top and bottom chords. (iv) The construction speed is fast. Spatial steel grid cassette structures can be constructed by steel vierendeel floor slab and steel grid wall (Figure 1).

This structure is suitable for multi-storey, large-span industrial and public buildings. At present, the steel vierendeel sandwich plate structure is widely used in China and has been applied to many pilot buildings (Figure 2) [3].

Steel vierendeel sandwich plate is mainly composed of top chords, bottom chords, and web members (Figure 3). The top and bottom chords mainly comprise T-shaped steel, and the web member is a square steel tube. The three sections are typically connected by weld (Figure 3 ), and the section size is usually not smaller than the width of the top chord and the bottom chord flanges. The connection area, which is called web member shear connections, joins the top chords and the bottom chords to a vertical bar. Commonly used connections in projects are types $\mathrm{A}$ and B (Figure 3) [4]. The vertical shear connection is the most complex component of the steel vierendeel sandwich plate 


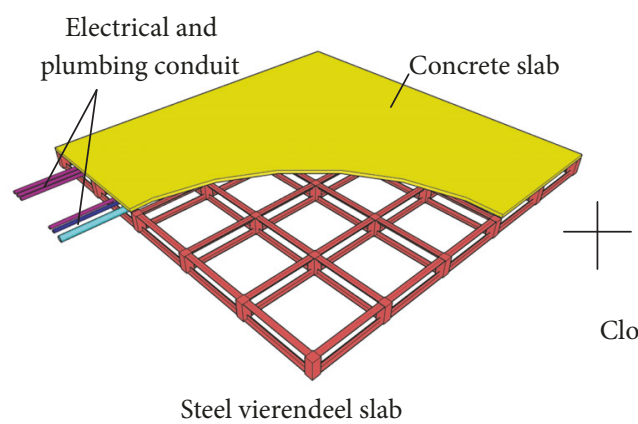

Steel vierendeel slab

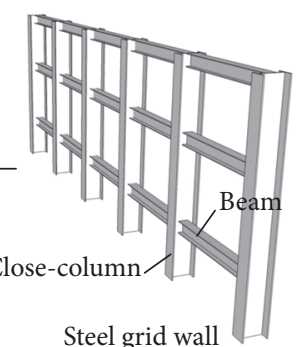

Steel grid wall

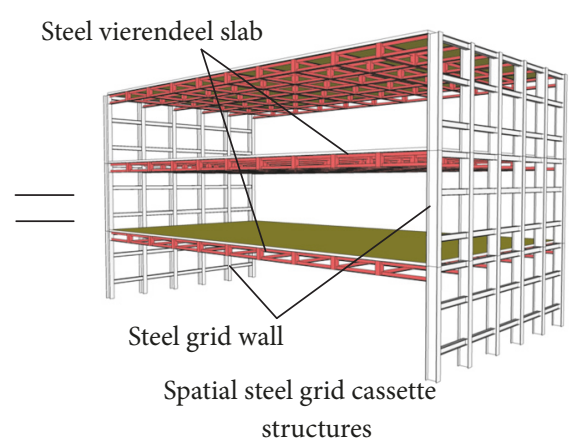

structures

FIGURE 1: Configuration of spatial steel grid cassette structures.
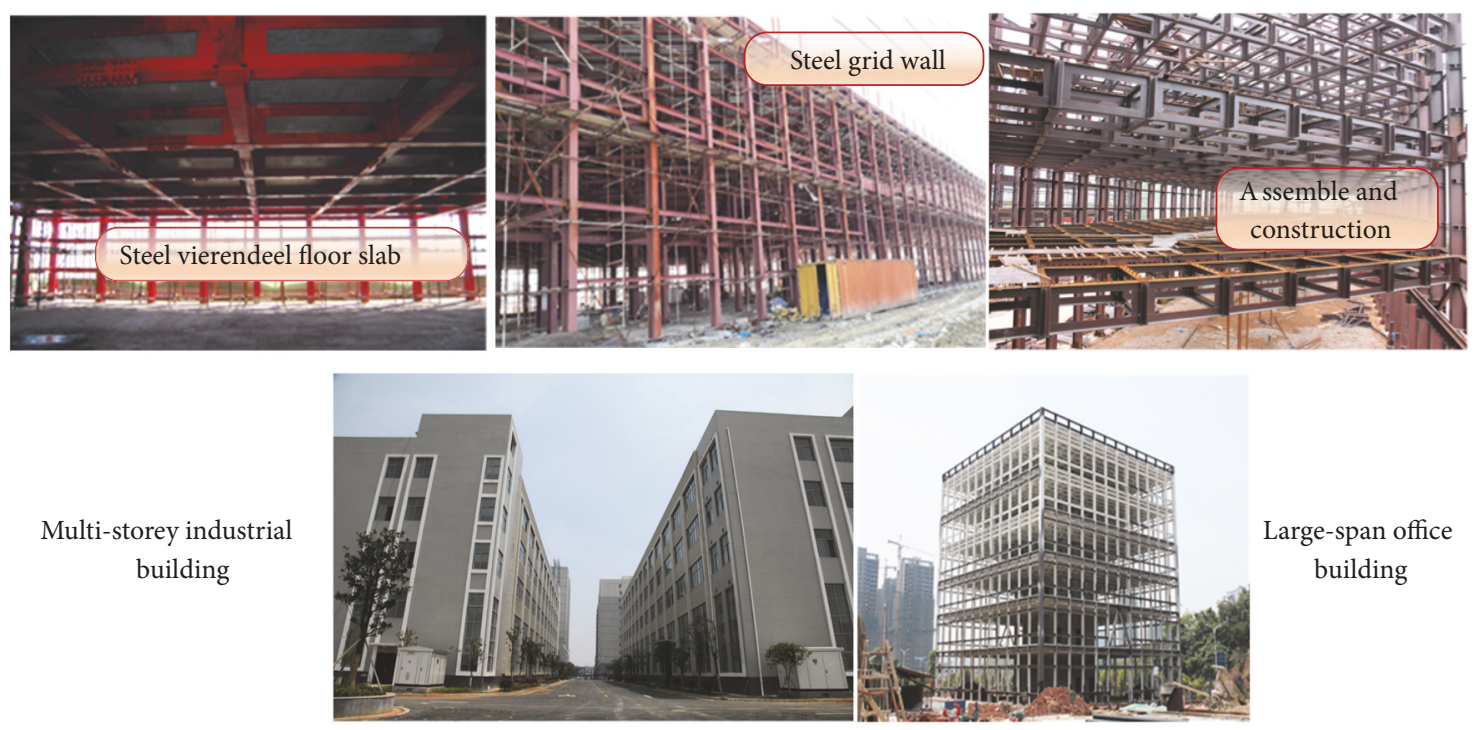

Figure 2: Application of steel vierendeel floor slab.

$[5,6]$. Chen Q. et al. [7] analyzed the static performance of the shear connectors in steel vierendeel sandwich plate through finite element method. The design parameters of the shear connectors considerably influenced floor stiffness. Bai Z. Q. et al. [8] carried out a one-way static loading test of two shear connectors models and concluded that type B connection displayed greater improvement in stiffness than type A. In summary, current research on the connection of steel vierendeel sandwich plate focuses on static performance.

Steel vierendeel sandwich plate is a large-span floor structure, and its dynamic catastrophic mechanism is an urgent problem to be studied [4]. Although many scholars conducted research on the dynamic performance of steel structure joints, most of them focused on the bending connection of frame structure beams and columns; thus far, few works have investigated the shear connection of the web [911]. Low frequency cyclic loading test is an effective method used to evaluate the dynamic performance of a structure [12]. This study aims to determine the dynamic performance of the shear connection of the vertical bar through low cyclic loading test.

\section{Connection Tests}

2.1. Design of Test Specimens. Vierendeel sandwich plate is crossed constituted by Vierendeel truss. The bearing capacity of the plate is controlled by shear force due to the large crosssection of its vertical bar [13]. A previous research tested a section of the open web with reference to literature to assess the performance of shear connectors [13] (Figure 4(a)). During the test, only the shearing action of the shear connectors under the horizontal force was considered. Figure 4(b) shows the mechanical model and boundary conditions of the intersection test.

Two full-scale test specimens were designed to examine the mechanical properties of A- and B-type connections. The dimensions of the specimens are based on actual engineering projects. The total height of the test piece $(h)$ is $600 \mathrm{~mm}$. The T-shaped section is used for the top and bottom chords, and the cross-section of the web member is a square tube. The different parts are welded by manual arc welding. Figure 5 shows the dimensions of the fillet. The type A connection specimen number is $\mathrm{T} 1$, and the type $\mathrm{B}$ connection number is T2. The specimen design and structure are shown in Figure 5, 

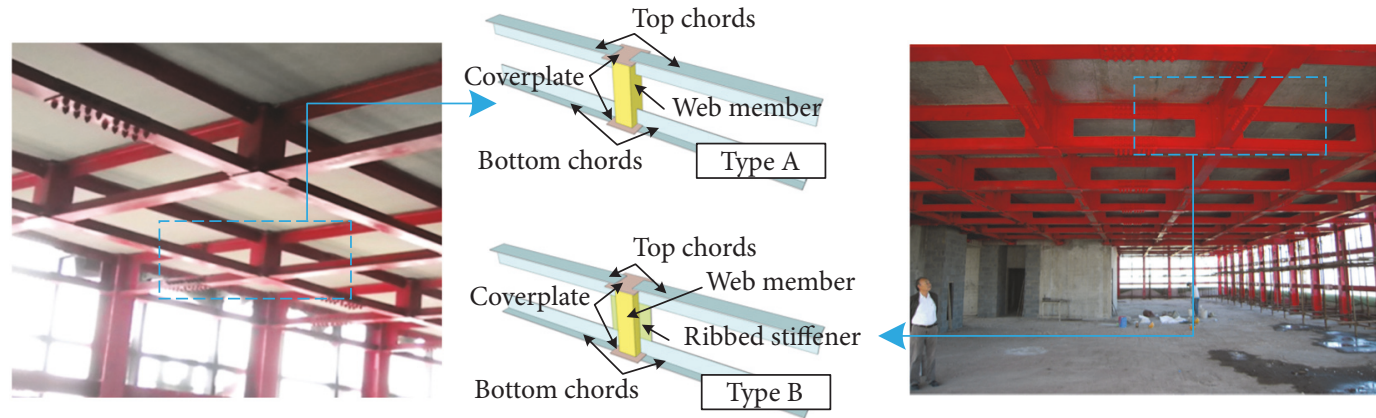

Figure 3: Types of connections.

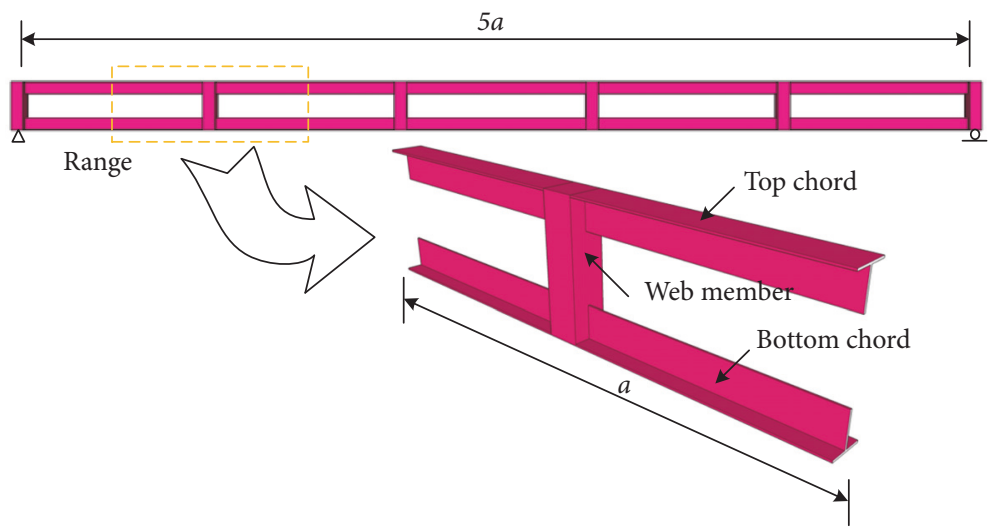

(a)

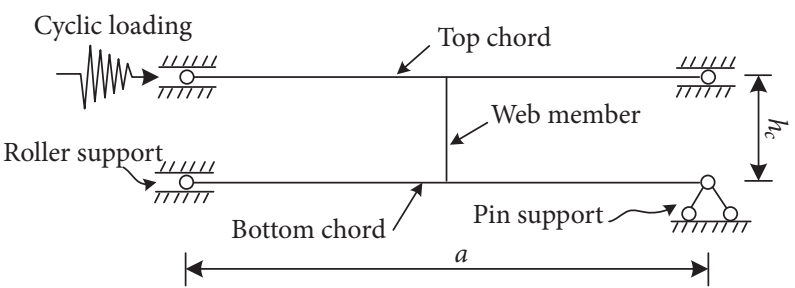

(b)

FIGURE 4: Mechanical model of the test. (a) Object of study. (b) Force diagram.

and the component size parameters are shown in Table 1. As shown in Figure $5, h_{c}$ is the T-shaped centroid distance. The test piece material used is Q235B steel.

A displacement gauge is used to measure the displacement of the specimen during loading in the $x$ direction for the top chord. The resistance strain gauge was used to measure the strain change of the web member connection during the test to determine the yield-destructive mechanism of the web connection. Referring to the stress distribution characteristics of the shear connectors, the strain gauge is placed at a portion where the stress of the test piece is great [14]. Each test piece has one displacement measuring point and 24 strain measuring points. Figure 6 shows the measuring point arrangement.

2.2. Test Set-Up and Loading. A set of reaction force brackets and loading systems were self-designed and fabricated on the basis of experimental boundary conditions (Figure 4(b)). The reaction force bracket and loading system were bolted to the reaction floor. Figure 7 shows the test loading device and its arrangement. The end A of specimens is box-shaped, and the side has a round hole, which is connected to the reaction frame through a pin to form a fixed hinge constraint. The end $\mathrm{B}$ of specimens has no circular hole and is connected to an actuator through a pin. The B-end, C-end, and D-end of the specimens are restrained by four sets of limit bearings that are independently designed with the reaction force bracket to form the movable hinge support constraint. The limit bearing comprises a bearing, a screw rod, and nuts. The limit bearing and the reaction force are fixed by screws and bolts, and the gap between the specimens can be adjusted. An alternating load is applied in the $x$ direction at the $\mathrm{B}$ end of the specimen by an actuator. The test protocols are determined according to the provisions of JGJ101-2015 [15] and the characteristics of this test. The reaction force data are collected through the load cell inside the actuator [11]. The actuator and power system 


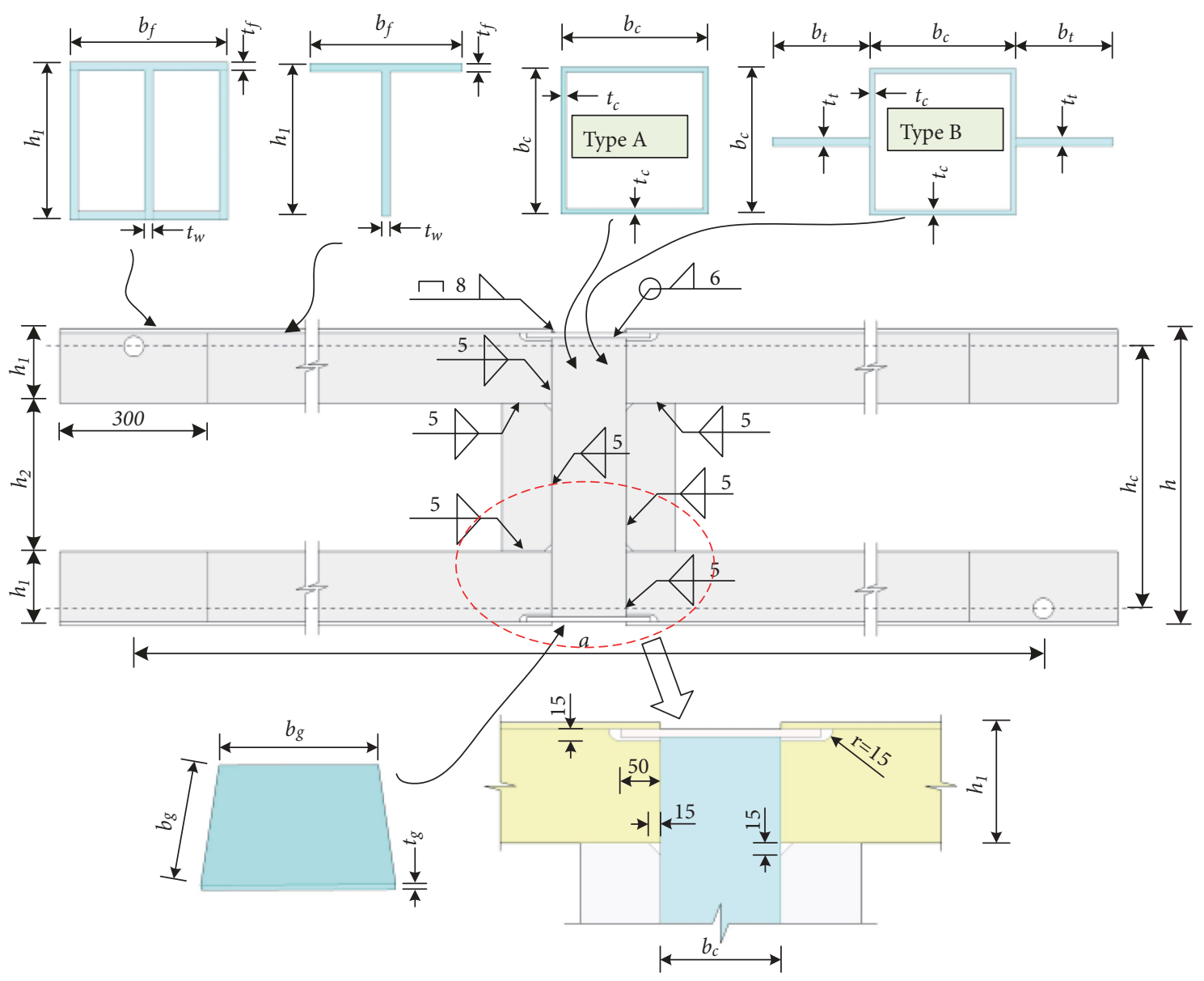

FIGURE 5: Details of specimens (Units: $\mathrm{mm}$ ).

TABLE 1: Design parameters of specimens.

\begin{tabular}{lcc}
\hline & \multicolumn{2}{c}{ Specimens } \\
size & $\mathrm{T} 1$ & $\mathrm{~T} 2$ \\
\hline$a(\mathrm{~mm})$ & 2400 & 2400 \\
$h_{1}(\mathrm{~mm})$ & 150 & 150 \\
$h_{2}(\mathrm{~mm})$ & 300 & 300 \\
$h_{c}(\mathrm{~mm})$ & 530 & 530 \\
$b_{f}(\mathrm{~mm})$ & 150 & 150 \\
$t_{f}(\mathrm{~mm})$ & 8 & 8 \\
$t_{w}(\mathrm{~mm})$ & 8 & 8 \\
$b_{c}(\mathrm{~mm})$ & 150 & 150 \\
$t_{c}(\mathrm{~mm})$ & 5 & 5 \\
$b_{t}(\mathrm{~mm})$ & - & 100 \\
$t_{t}(\mathrm{~mm})$ & - & 8 \\
$b_{g}(\mathrm{~mm})$ & 250 & 250 \\
$t_{g}(\mathrm{~mm})$ & 10 & 10 \\
\hline
\end{tabular}

are purchased from MTS. Figure 8(a) shows the test protocol of specimen T1, and Figure 8(b) shows the test protocol of specimen T2. Every load cycle is 6 minutes long. All the test data are collected by static signal test and analysis system (model: TZT3826E), while the sampling frequency is $10 \mathrm{~Hz}$.
2.3. Material Properties. The specimens are all made of $\mathrm{Q} 235 \mathrm{~B}$ steel. The same batch of steel plate-shaped test pieces was simultaneously produced in the process of making specimens. Figure 9 shows the specimen used for material performance test. Test yield strength $(f y)$, ultimate strength $(f u)$, and elastic modulus (Es) were measured by homotaxial tensile test. Table 2 shows the test piece parameters and test results.

\section{Test Results and Discussion}

3.1. Test Phenomenon and Failure Modes of Specimens. The two types of specimens appeared exhibited obvious elastic properties at the beginning of loading.

When the displacement was loaded to $28.5 \mathrm{~mm}$, specimen T1 showed remarkable sagging or convex deformation on the joint that connected the side of the web plate and the web of the chord (Figure 10(a)). When the displacement was loaded to approximately $32.5 \mathrm{~mm}$, microcracks appeared in the heat-affected zone of the joint between the chord web and the side of the web member (Figure 10(b)). The loading process is accompanied by the sound of "Zhizhi," and the crack is continuously increased with cyclic loading. Part of the strain gauge failed to fall off. When the displacement was loaded to $36.5 \mathrm{~mm}$, the cracks at the four joints were 


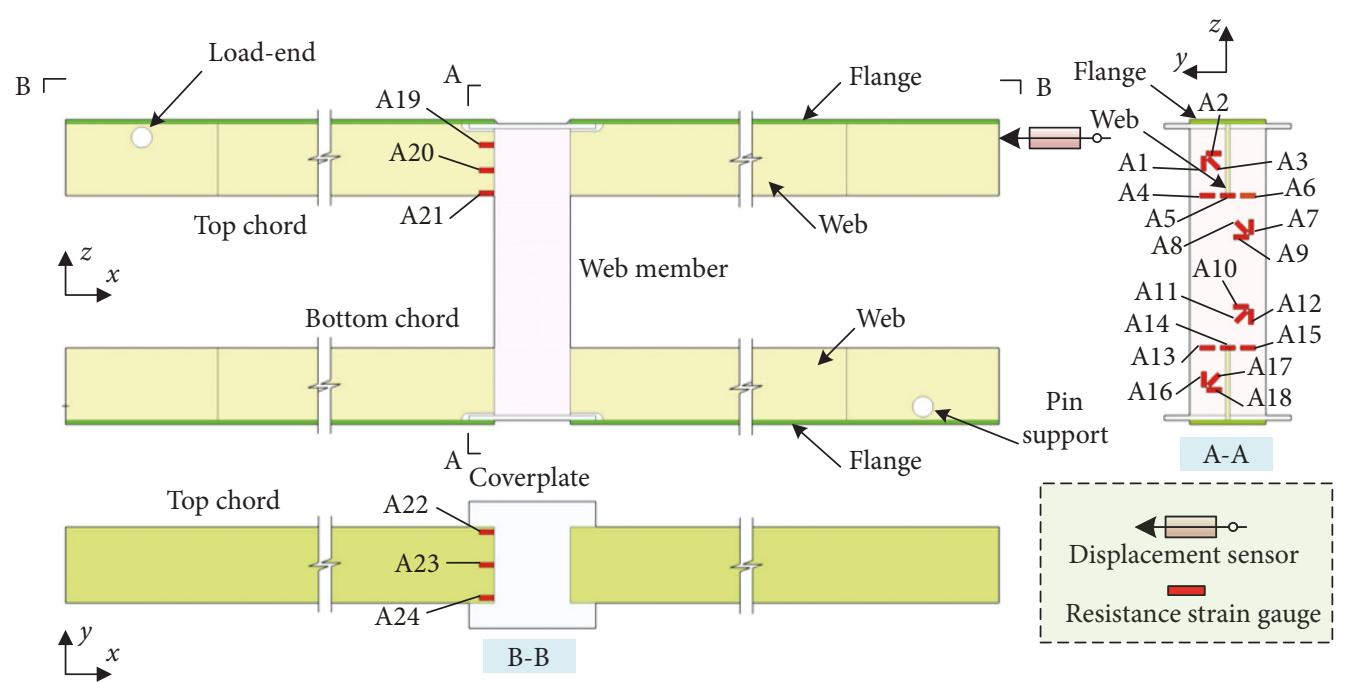

(a)

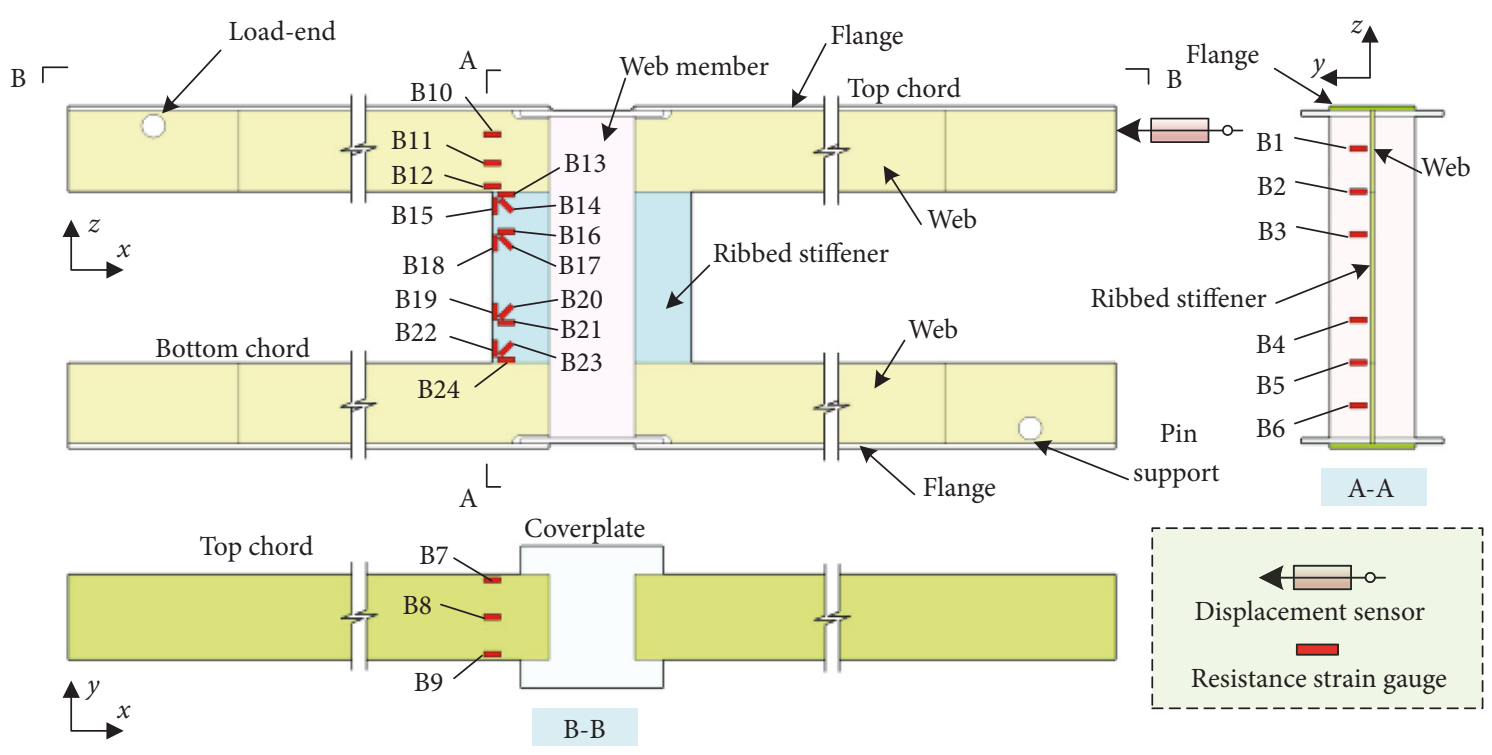

(b)

FIGURE 6: Arrangement of displacement sensors and strain gauges. (a) Specimen T1. (b) Specimen T2.

TABLE 2: Mechanical property index of steel.

\begin{tabular}{lccc}
\hline & Square tube & T-section steel & Cover plate \\
& S-1 & S-2 & S-3 \\
\hline$H(\mathrm{~mm})$ & 50 & 50 & 50 \\
$C(\mathrm{~mm})$ & 17 & 17 & 17 \\
$L_{0}(\mathrm{~mm})$ & 84 & 84 & 84 \\
$a_{0}(\mathrm{~mm})$ & 5 & 8 & 10 \\
$D_{0}(\mathrm{~mm})$ & 30 & 30 & 30 \\
$b_{0}(\mathrm{~mm})$ & 20 & 20 & 20 \\
$f_{\mathrm{y}}(\mathrm{MPa})$ & 232 & 261 & 255 \\
$f_{\mathrm{u}}(\mathrm{MPa})$ & 393 & 410 & 402 \\
$E_{\mathrm{s}}(\mathrm{MPa})$ & $2.03 \mathrm{e}^{5}$ & $2.11 \mathrm{e}^{5}$ & $2.09 \mathrm{e}^{5}$ \\
\hline
\end{tabular}

successively expanded into U-shaped cracks (Figure 10(c)), and the bearing capacity of the members reaches a maximum of $52.3 \mathrm{kN}$. When displacement was loaded to the maximum set displacement of $42.5 \mathrm{~mm}$, except for the increase of the crack at the joint of the chord and the web, the microcrack appeared in the heat-affected zone, where the cover and the web were connected, and the bearing capacity descended. In general, when damage occurred, the bearing capacity of the specimen $\mathrm{T} 1$ did not significantly decrease. Thus, plastic deformational development was not completed.

When the displacement was loaded to $18.5 \mathrm{~mm}$, microcracks appeared at the joint between the stiffener rib and the web of the chord in specimen T2 (Figure 11(a)). With the cyclic loading, cracks appeared at the four joints, and the specimen performed the elastoplastic stage. When the displacement was loaded to $20.5 \mathrm{~mm}$, the crack on the web of the chord began to expand obliquely and increased (Figures 11(a) and 11(b)). When the displacement was loaded to 22.5 $\mathrm{mm}$, the bearing capacity reached a maximum of $162.5 \mathrm{kN}$. 


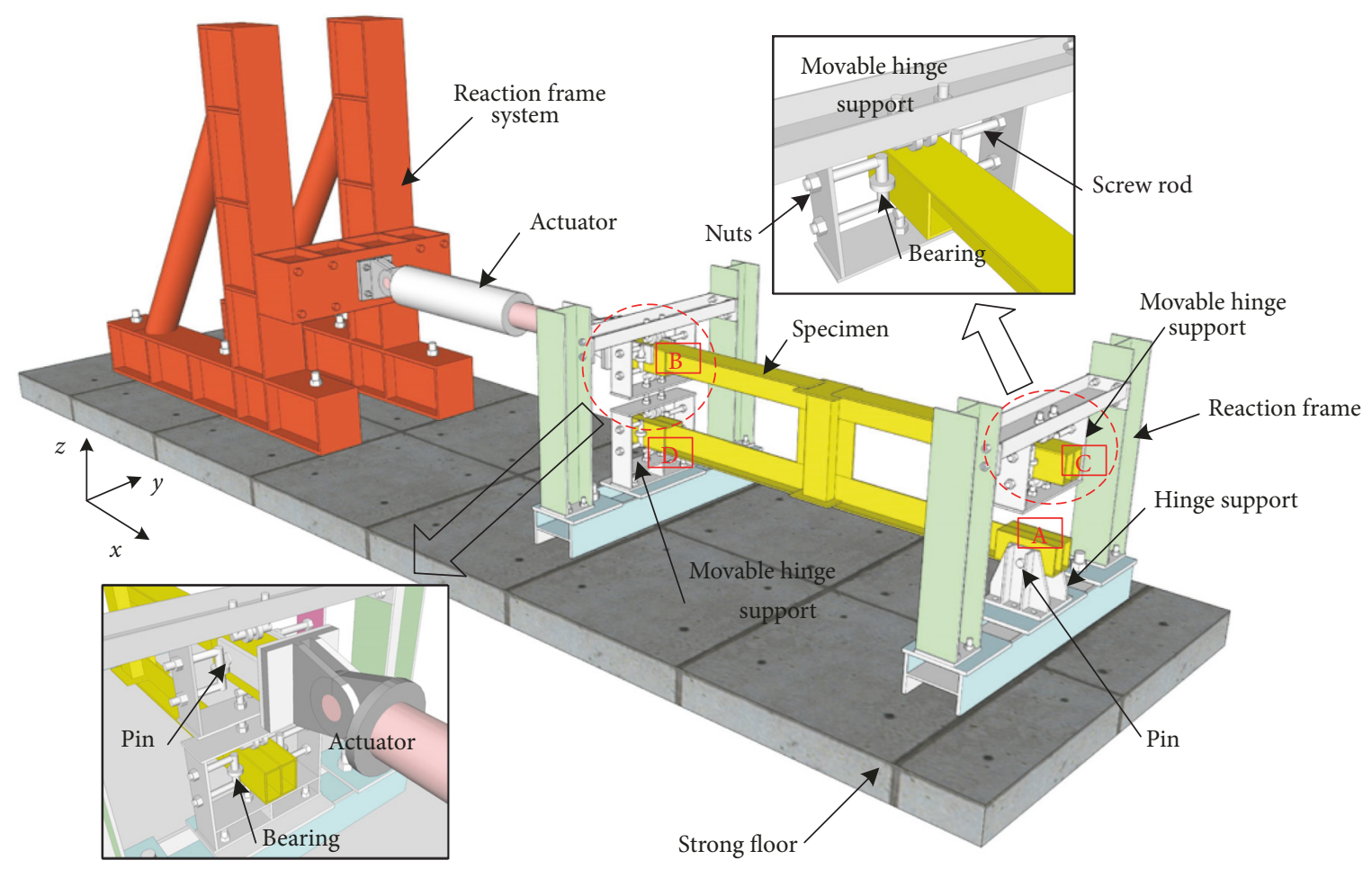

(a)
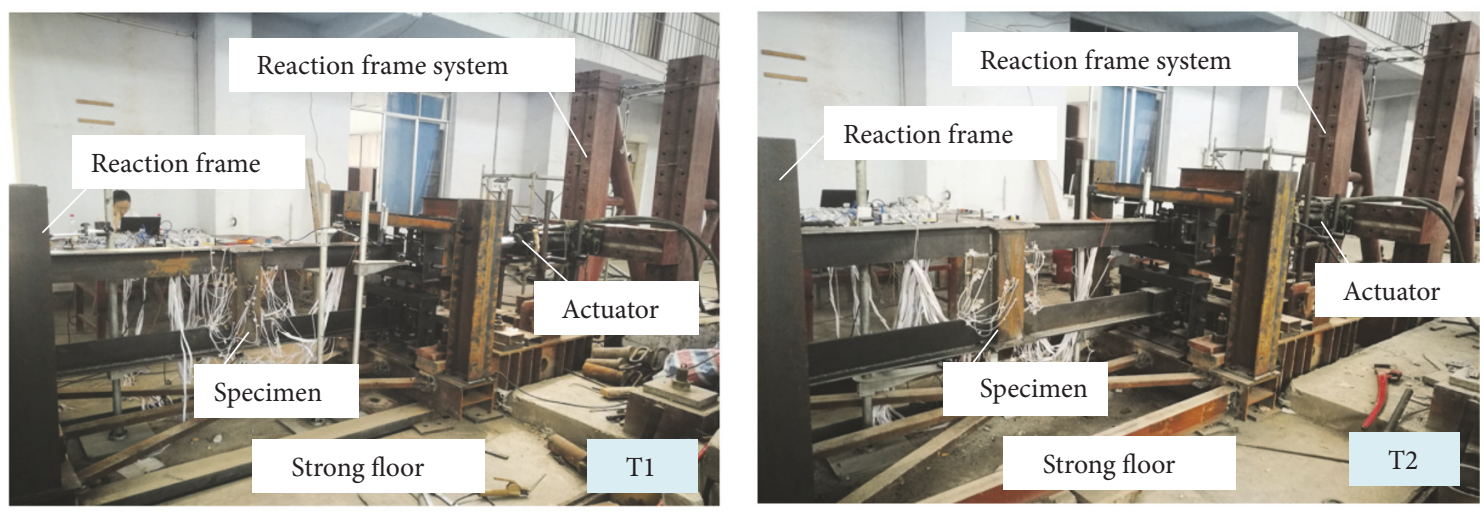

(b)

Figure 7: Schematic of the test set-up. (a) Self-design of loading device. (b) Test photos.

When the displacement was loaded to $24.5 \mathrm{~mm}$, the joint between the stiffener and the web began to buckle. The bearing capacity of the specimen entered the descending phase, and the crack on the web of the chord expanded rapidly. When the displacement was loaded to a maximum of $26.5 \mathrm{~mm}$, the whole stiffening plate exhibited an " $\mathrm{S}$ "type buckling, and the buckling deformation is shown in Figure 11(d). After destroying the specimen, the bearing capacity is obviously reduced, indicating that the plastic deformation development is perfect.

3.2. Hysteretic Curves. The hysteresis curve is a comprehensive reflection of the seismic performance of the structure and the main basis for structural seismic elastoplastic dynamic response analysis [16]. According to the literature [17-19], the initial geometric defects and residual stress only affect the initial maximum load reduction of the member and poses minimal effect on the subsequent hysteresis performance of the member. Therefore, the initial geometric defects and residual stress of the member are not considered in this paper. The hysteresis performance of the web connection node is mainly contributed by the node domain and the two parts of the rod. Therefore, the total reaction force $P$ of the loading point is characterized by the horizontal displacement $\Delta$ of the rod loading point. The total reaction force $\mathrm{P}$ of the node is the load applied by the actuator, and the horizontal displacement of the loading point is the horizontal displacement of the actuator. The load P- $\Delta$ hysteresis curves for specimen T1 and 


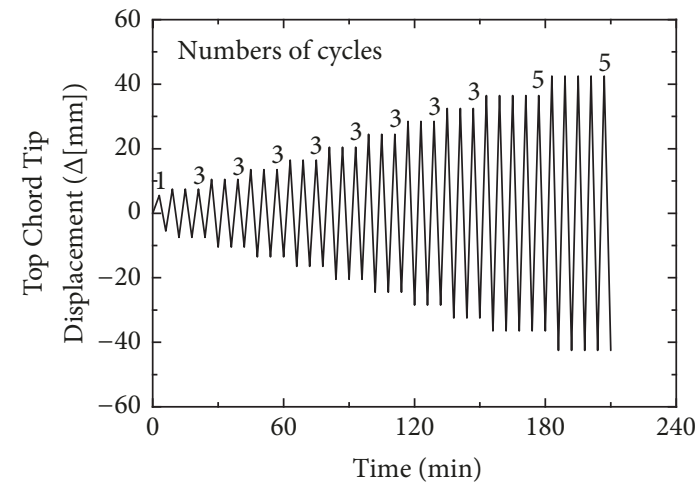

(a)

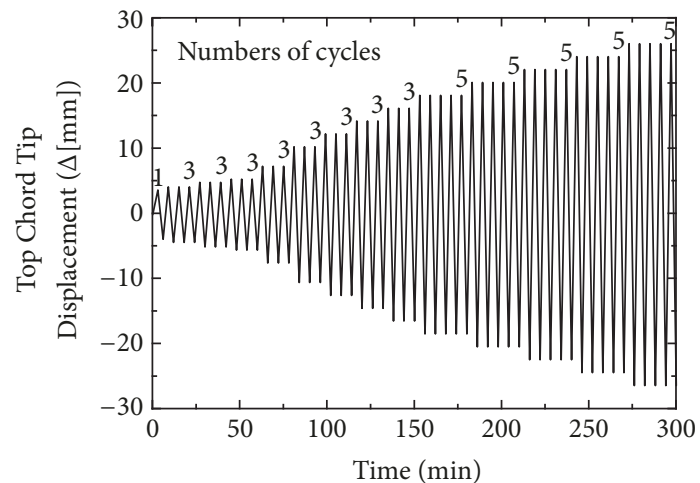

(b)

Figure 8: Test protocols. (a) Specimen T1. (b) Specimen T2.

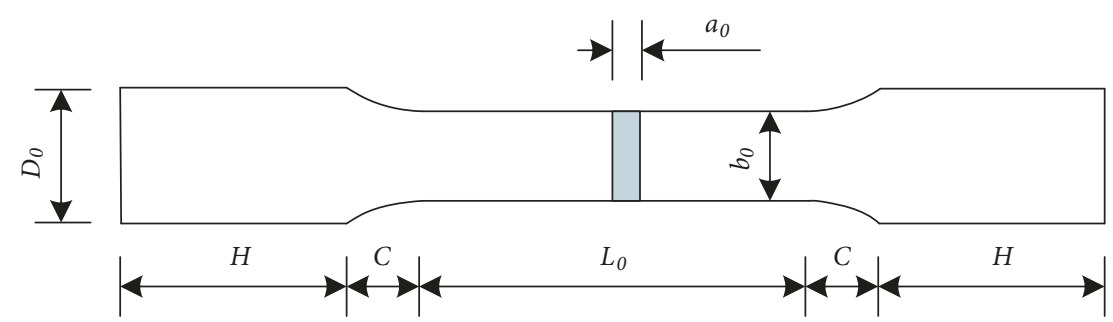

(a)

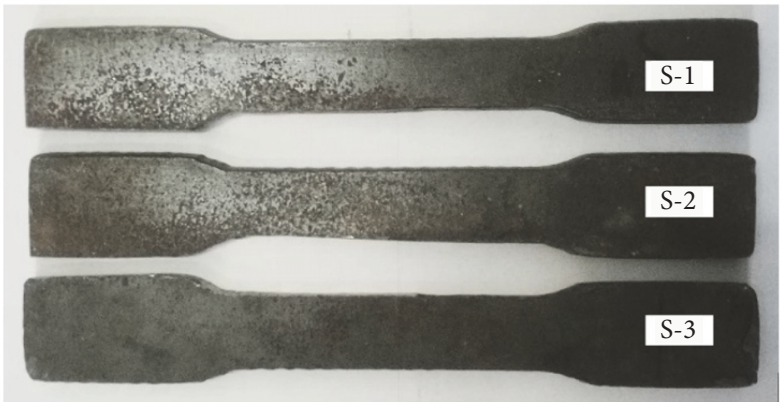

(b)

FIGURE 9: Test specimen details. (a) Size indication. (b) Specimen of material tests.

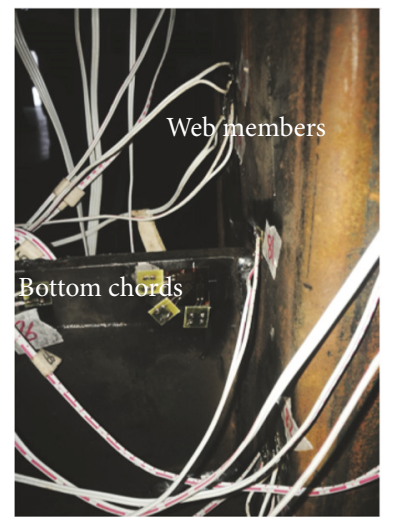

(a)

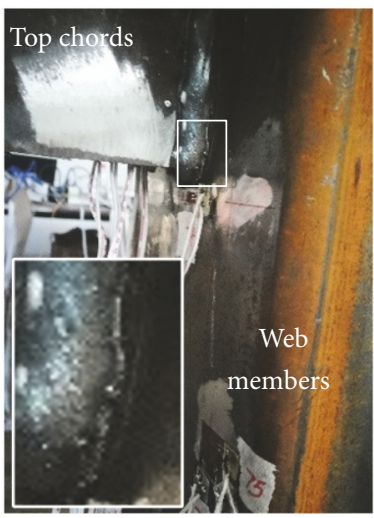

(b)

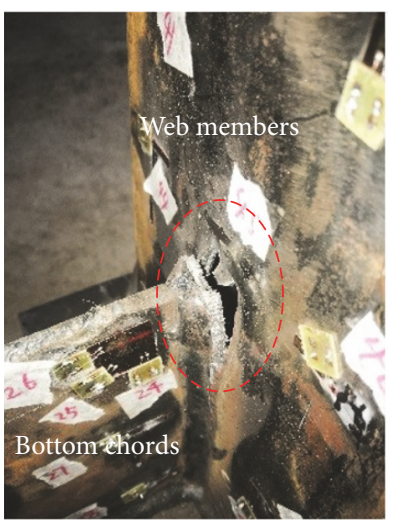

(c)

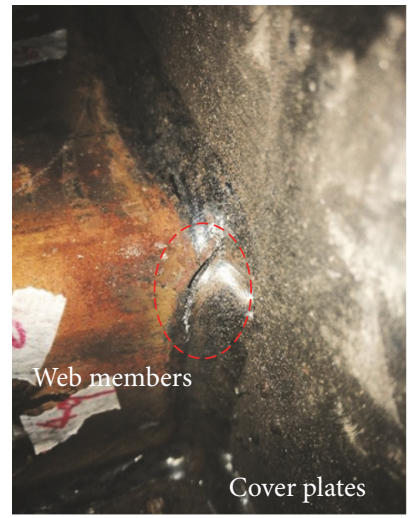

(d)

FIgURE 10: Test phenomenon and failure modes of specimen T1. 


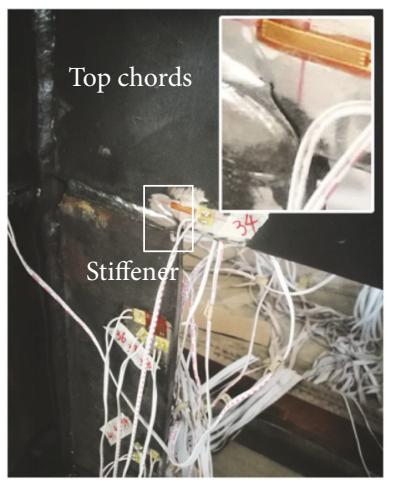

(a)

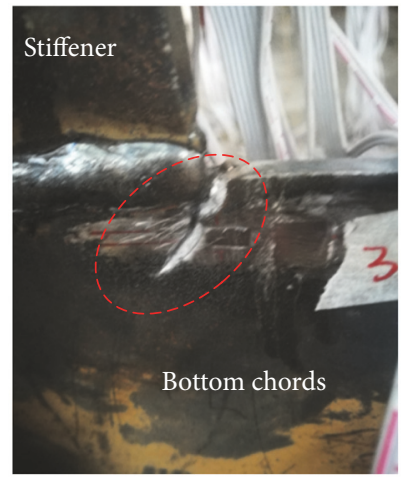

(b)

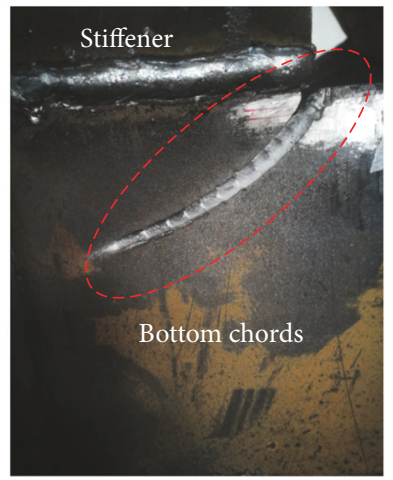

(c)

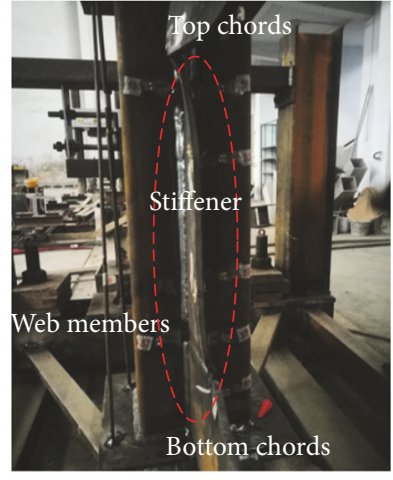

(d)

FIGURE 11: Test phenomenon and failure modes of specimen T2.

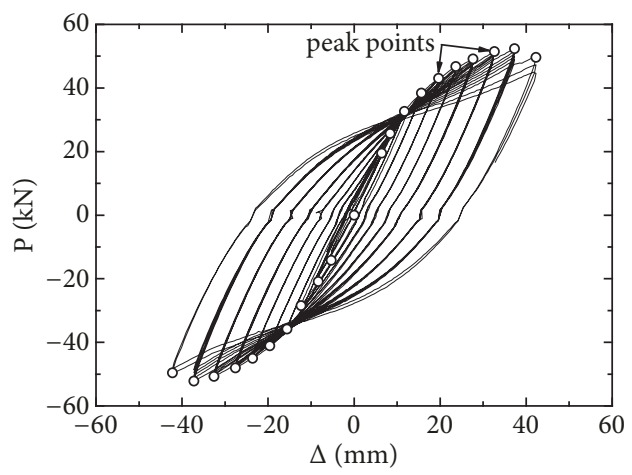

(a)

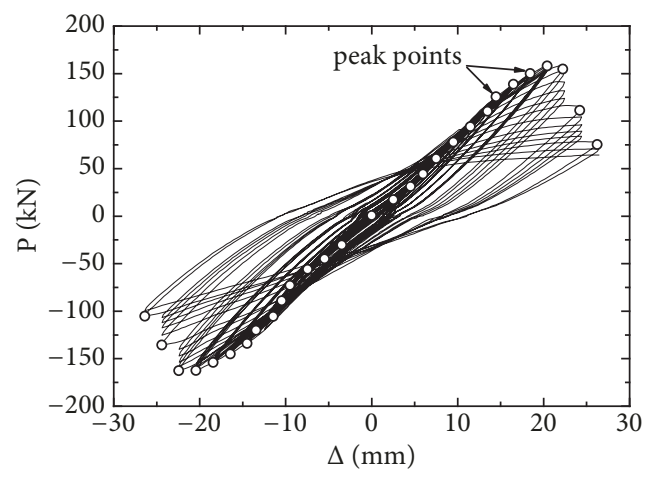

(b)

FIgURE 12: Experimental hysteresis curves for specimens. (a) Specimen T1. (b) Specimen T2.

T2 are shown in Figures 12(a) and 12(b), respectively. Figure 12 shows the following.

(1) The hysteresis loops of the two connected specimens are similar in shape, all of which are spindle-shaped and no pinching phenomenon are observed.

(2) At the initial stage of loading, the specimen is in an elastic working status so that the development of the P- $\Delta$ curve is basically linear. The loading and unloading curves are basically coincident, that is, the residual deformation is substantially zero. Residual deformation increases with load due to the drumming or yielding of steel in the node domain, and the hysteresis loop area gradually increases, thereby forming a full shuttle shape. The reason is that the yielding extent of the pipe wall in the node zone is gradually increased, and the stiffness is also decreased as deformation increased.

(3) In contrast with specimen T2, the hysteresis curve of specimen $\mathrm{T} 1$ is fuller and has stronger energy consumption.

3.3. Skeleton Curve and Bearing Capacity. The skeleton curve is the trajectory of the maximum peak of P- $\Delta$ curve at the loading end under each cyclic load. In this study, the skeleton curve of the specimens can be obtained by connecting the load peak points of various hysteretic curves of the specimen successively. The peak points used to obtain the skeleton curve are shown in Figure 12. Figures 13(a) and 13(b) show the skeleton curve of specimens $\mathrm{T} 1$ and $\mathrm{T} 2$, respectively. The buckling displacement and yield load of the structure are obtained from the skeleton curve using the energy method [20]. Table 3 shows the skeleton characteristic values of each specimen.

When the loading for specimen $\mathrm{T} 1$ starts, the skeleton curve is a straight line and is basically in an elastic working status. As the load increases to approximately 0.65 of the ultimate load, the skeleton curve is gradually bended toward the displacement axis, and the slope of the curve is gradually decreased. After the peak load, the load does not drop significantly. When the loading for specimen T2 starts, the skeleton curve is a straight line and is basically in an elastic working status. As the load is increased to approximately 0.85 of the ultimate load, the skeleton curve begins to bend toward the displacement axis, and the slope of the curve is decreased. After the peak load, the load is dropped significantly.

Table 3 shows the experimental values of the bearing capacity of the two types of joint specimens. Under the condition that the basic parameters of the structure are consistent, the bearing capacity of specimen $\mathrm{T} 2$ is approximately three times that of specimen T1. The connection method of the vertical rod poses significant influence on the bearing capacity of the specimen. 
TABLE 3: The measured value of bearing capacity, displacement, ductility coefficient, and final damage.

\begin{tabular}{|c|c|c|c|c|c|c|c|c|c|}
\hline \multirow{2}{*}{ Specimen } & \multirow{2}{*}{ Loading direction } & \multicolumn{2}{|c|}{ Yield point } & \multicolumn{2}{|c|}{ Ultimate point } & \multicolumn{2}{|c|}{ Damage point } & \multirow{2}{*}{$\mu$} & \multirow{2}{*}{$D$} \\
\hline & & $\mathrm{P}_{y} / \mathrm{kN}$ & $\Delta_{y} / \mathrm{mm}$ & $\mathrm{P}_{u} / \mathrm{kN}$ & $\Delta_{u} / \mathrm{mm}$ & $\mathrm{P}_{d} / \mathrm{kN}$ & $\Delta_{d} / \mathrm{mm}$ & & \\
\hline \multirow{2}{*}{$\mathrm{T} 1$} & $+x$ & 32.60 & 11.70 & 52.37 & 37.30 & 49.60 & 42.29 & 3.19 & \multirow{2}{*}{0.66} \\
\hline & $-x$ & 28.47 & 12.32 & 52.20 & 37.26 & 49.61 & 42.24 & 3.02 & \\
\hline \multirow{2}{*}{$\mathrm{T} 2$} & $+x$ & 95.88 & 9.50 & 156.71 & 20.41 & 110.05 & 24.20 & 2.15 & \multirow{2}{*}{0.61} \\
\hline & $-x$ & 92.33 & 9.48 & 162.67 & 22.41 & 135.97 & 24.39 & 2.36 & \\
\hline
\end{tabular}

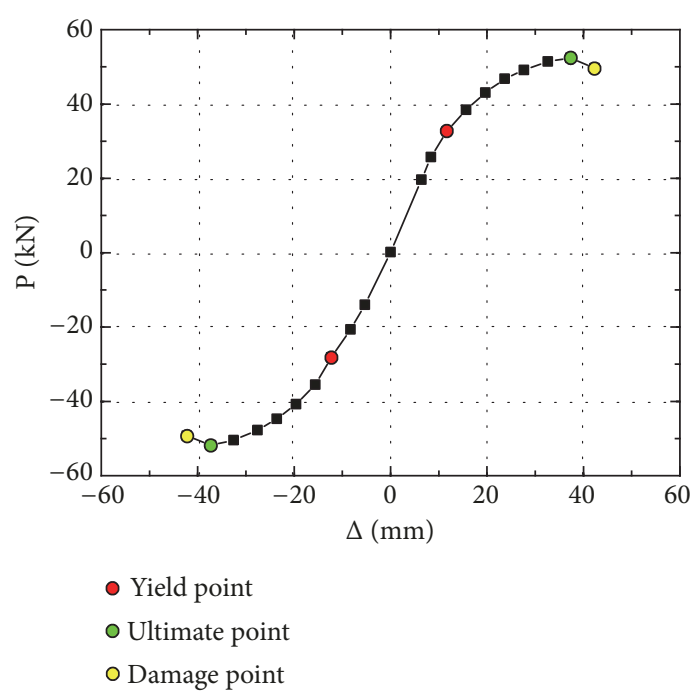

(a)

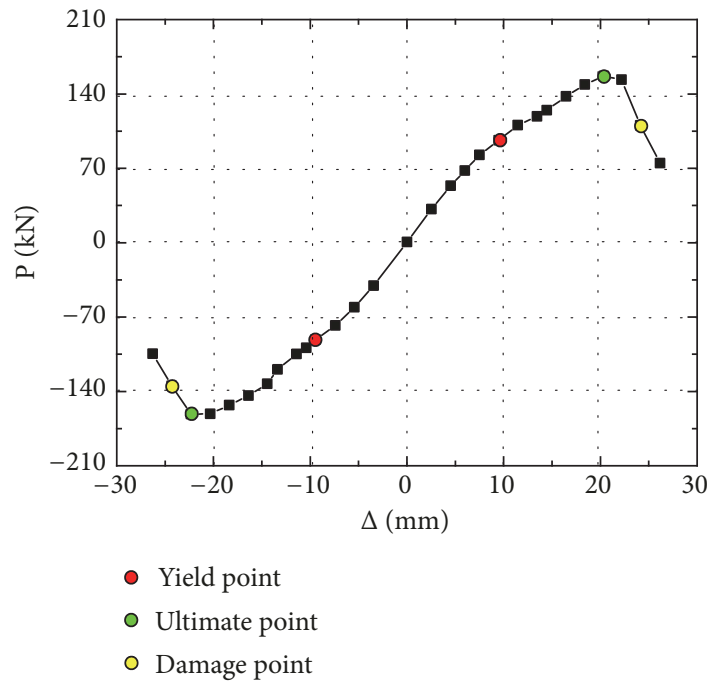

(b)

Figure 13: Skeleton curves. (a) Specimen T1. (b) Specimen T2.

3.4. Stiffness and Ductility. The stiffness of the connected specimen is related to the displacement and the number of cycles. As the alternating load and displacement amplitude increase, plastic deformation develops, and stiffness gradually degenerates.

In this study, the stiffness of the specimen is expressed by the secant stiffness that corresponds to the displacement in the same stage [15]. $K_{i}$ is the stiffness of the specimen in $i$ load cycle, which can be calculated by

$$
K_{i}=\frac{\left|+F_{i}\right|+\left|-F_{i}\right|}{\left|+\Delta_{i}\right|+\left|-\Delta_{i}\right|}
$$

where $F_{i}$ is the peak load of the specimen in $i$ load cycles; $\Delta_{i}$ is the displacement of the specimen in $i$ load cycles.

Figure 14(a) shows the stiffness degradation curve of specimen T1, and Figure 14(b) shows the stiffness degradation curve of specimen T2. Figure 14(a) shows that as $\Delta$ increases, the stiffness of specimen $\mathrm{T} 1$ deteriorates, and stiffness degradation is severe when control displacement is large. Figure 14(b) shows that when the control displacement is between $-20 \mathrm{~mm}$ and $+20 \mathrm{~mm}$, the stiffness curve of specimen T2 is relatively flat. When the control displacement is greater than $+20 \mathrm{~mm}$ or less than $-20 \mathrm{~mm}$, stiffness is rapidly degraded. The stiffness of specimen T2 is approximately 3 times that of specimen $\mathrm{T} 1$.

The load and displacement values of yield points, limit points, and damage points in Figure 13 are listed in Table 3.
The yield point is calculated by the energy method [20]. The peak points of the curve in Figure 13 are defined as limit points. The corresponding points on the skeleton curves are defined as damage points while the load decreases to $85 \%$ of the limit load [15].

The ductility coefficient $\mu$ is a measure of structure ductility [21], which is expressed as the ratio of the ultimate displacement of the structure to the yield displacement:

$$
\mu=\frac{\Delta_{u}}{\Delta_{y}}
$$

where $\Delta_{u}$ is the ultimate displacement and $\Delta_{y}$ is the yield displacement. Table 3 shows the main calculation results. Table 3 shows that the ductility $\mu$ of $\mathrm{T} 1$ specimen is between 3.0 and 3.2, and the ductility $\mu$ of $\mathrm{T} 2$ specimen is between 2.1 and 2.4. This finding shows that the two connection methods exhibit good ductility, and the ductility of type A connection is better than that of type B connection.

The damage of the connected specimen response can be obtained through the stiffness degradation value in each load cycle:

$$
D_{i}=\frac{\Delta K_{i}}{K_{0}},
$$

where $D_{i}$ is the damage of the specimen in each load cycle; $K_{0}$ is the stiffness of the joint specimen; and $\Delta K_{i}$ is the stiffness 


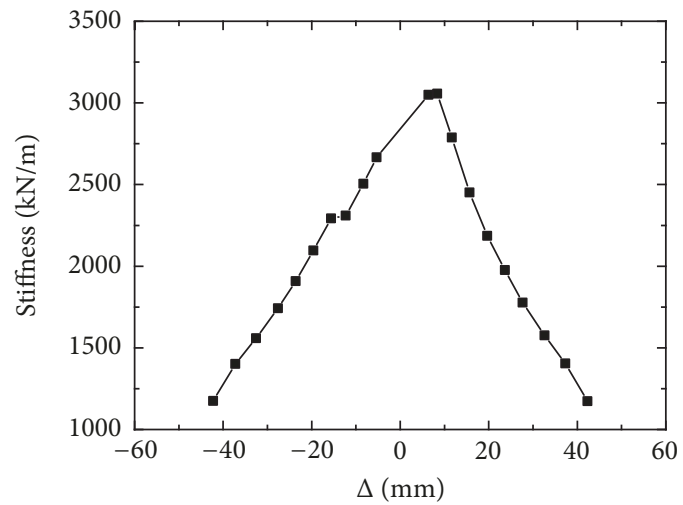

(a)

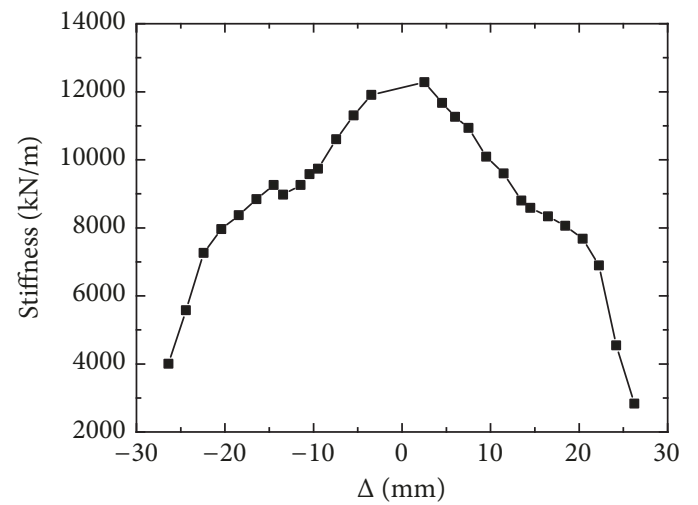

(b)

FIgURE 14: Stiffness degeneration curve. (a) Specimen T1. (b) Specimen T2.

degradation value of the joint in each load cycle, which can be calculated by

$$
\Delta K_{i}=K_{i}-K_{i-1},
$$

where $K_{i}$ and $K_{i-1}$ are the stiffness of the specimen in $i$ and $i$-1 load cycles, respectively. The final damage of the specimen can be obtained by summing $D_{i}$ :

$$
D=\sum_{i=1}^{n} D_{i}
$$

where $n$ is the total number of cycles when the specimen is loaded to failure.

Table 3 shows the cumulative damage of the specimen under the action of alternating load, indicating that the final damage $D$ of specimen $T 1$ is slightly greater than that of specimen T2. The elastoplastic properties of the material are fully exerted.

3.5. Energy Dissipation Performance. Energy dissipation capacity and damping are important indicators for measuring structural dynamic performance. The energy dissipation capacity is measured by the area surrounded by the hysteresis curve of load deformation and is usually evaluated by the energy dissipation coefficient $\mathrm{E}$ and/or the equivalent viscous damping coefficient $\zeta_{e q}$. The calculation is presented as follows:

$$
\begin{aligned}
\mathrm{E} & =\frac{S_{(\widehat{A B C}+\widehat{C D A})}}{S_{(\mathrm{OBE}+\mathrm{ODF})}} \\
\zeta_{e q} & =\frac{1}{2 \pi} \cdot \frac{S_{(\widehat{A B C}+\widehat{C D A})}}{S_{(\mathrm{OBE}+\mathrm{ODF})}},
\end{aligned}
$$

where $S_{(\widehat{A B C}+\widehat{C D A})}$ is the area surrounded by the hysteresis curve in Figure $15 ; S_{(\widehat{O B E}+O D F)}$ is the sum of the area of the triangle OBE and the triangle ODF in Figure 15. The energy consumption of the yield point, peak point, and damage point is shown in Table 4 . Table 4 shows that the energy dissipation coefficient and the equivalent viscosity damping coefficient of each specimen increase with displacement. The energy consumption of specimen $\mathrm{T} 1$ is better than that of specimen T2.

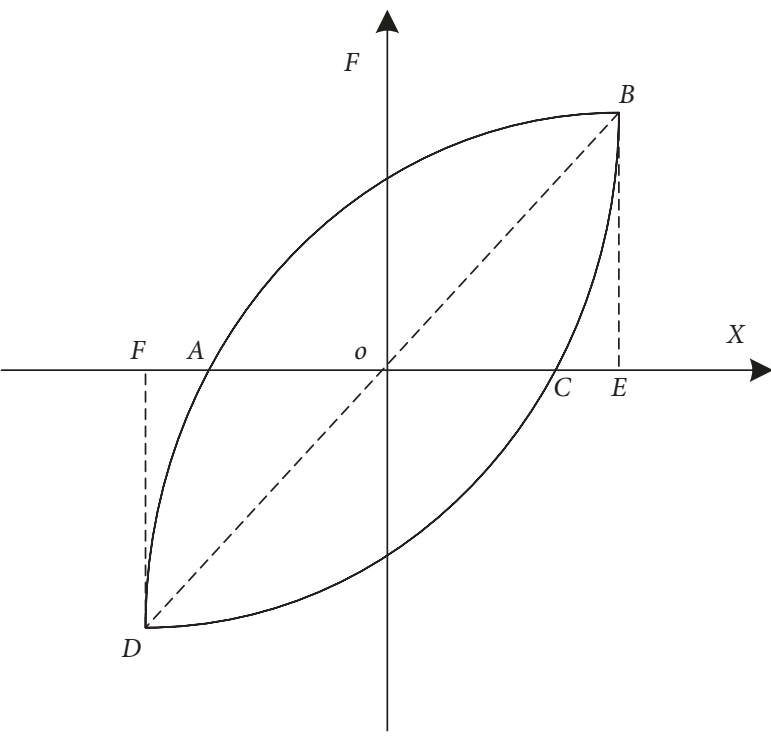

FIGURE 15: Load-displacement hysteretic loop.

3.6. Strain Analysis. The strain measuring points in Figure 6 were monitored during the test. Figure 16 shows the distribution of specimen T1 strain along with loading displacement changes. Figure 17 shows the distribution of specimen T2 strain with loading displacement changes.

Figure 16 shows that the type A connection is connected to the end portion of the web in the upper chord and the web side. Stress concentration occurs. Strain is larger when the end portion is close. The main strain direction on the side wall is radial with the intersection of the edge of the chord web and the side wall of the vertical rod as the origin. The end of the upper chord is connected to the sidewall of the web, where the flange strain is large in the edge and small in the middle. The end of the upper chord is connected to the sidewall of the web, and the end of the web is close to the flange, where the strain at the measuring point is smaller, and the strain away from the flange is larger. In general, when the loading displacement reaches $\Delta_{y}$, most of the measured strain at the sidewall reaches yield strain, and the strain at the end of the upper chord is still in the elastic phase. When 
TABLE 4: Energy dissipation coefficient and equivalent viscous damping coefficient.

\begin{tabular}{lcccccc}
\hline \multirow{2}{*}{ Specimen } & \multicolumn{2}{c}{ Yield point } & \multicolumn{2}{c}{ Ultimate point } & \multicolumn{2}{c}{ Damage point } \\
& $\mathrm{E}$ & $\zeta_{\text {eq }}$ & $\mathrm{E}$ & $\zeta_{\text {eq }}$ & $\mathrm{E}$ & \multicolumn{1}{c}{$\zeta_{\text {eq }}$} \\
\hline $\mathrm{T} 1$ & 0.347 & 0.055 & 1.173 & 0.187 & 0.233 \\
$\mathrm{~T} 2$ & 0.198 & 0.032 & 0.404 & 0.064 & 0.859 & 0.137 \\
\hline
\end{tabular}

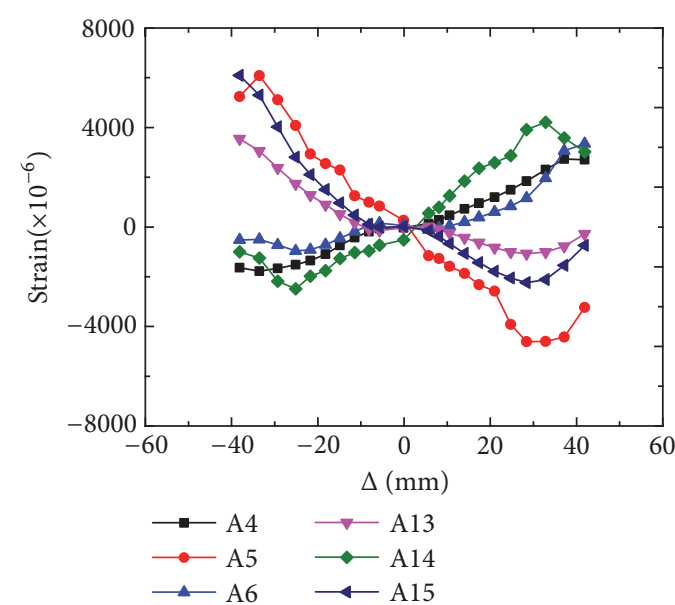

(a)

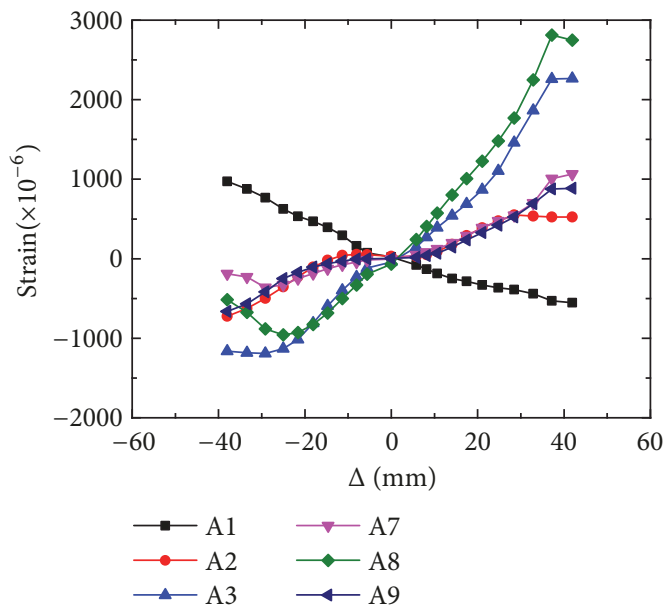

(c)

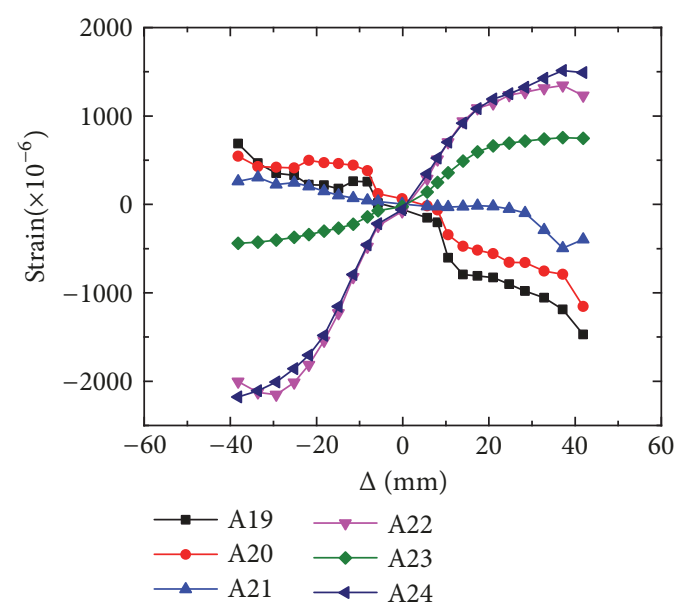

(b)

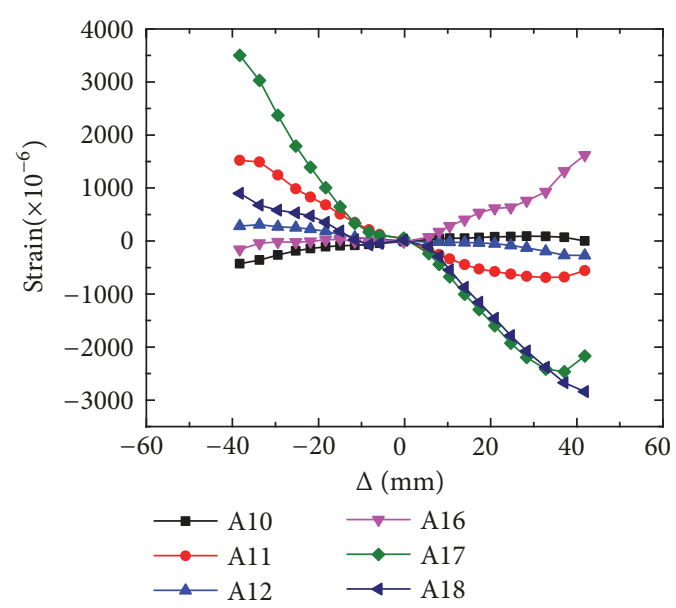

(d)

Figure 16: Strain of specimen T1. (a) The part of web near the weld. (b) Top chord. (c) The part of web near the top chord. (d) The part of web near the bottom chord.

the loading displacement reaches $\Delta_{u}$, most of the measured strain of the sidewall reaches the peak value, and the strain at the end of the chord gradually reaches yield strain. When the loading displacement reaches $\Delta_{d}$, the stress redistribution occurs due to the large crack at the joint between the sidewall and the chord web. The strain at the measuring point shows a downward trend, and the strain at the end of the chord continues to increase.

The strain on the stiffening plate in the loading process among the measuring points of the type $\mathrm{B}$ connection is the largest, followed by the end of the chord and the side wall strain of the web (Figure 17). In general, when the loading displacement reaches $\Delta_{y}$, the strain at the point where the stiffener is connected to the web of the chord initially reaches yield strain, and the strain at the joint of the bar and the stiffener bar also rapidly reach the yield strain. However, the other points still remain in the elastic stage. When the loading displacement reaches $\Delta_{u}$, the strain at the point where the stiffener is connected to the web of the chord reaches the peak, and the strain at the other points continues to increase. When the loading displacement reaches $\Delta_{d}$, the strain at the point where the stiffener is connected to the web of the chord is gradually decreased due to the overall buckling deformation of the stiffener and the chord web.

\section{Conclusions}

The main conclusions are summarized on the basis of cyclic pseudo-static seismic testing of web member shear connections, as follows: 


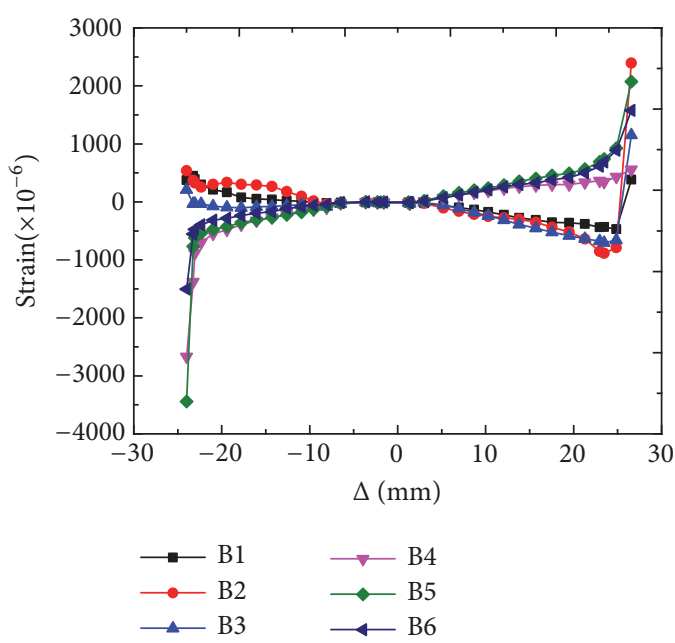

(a)

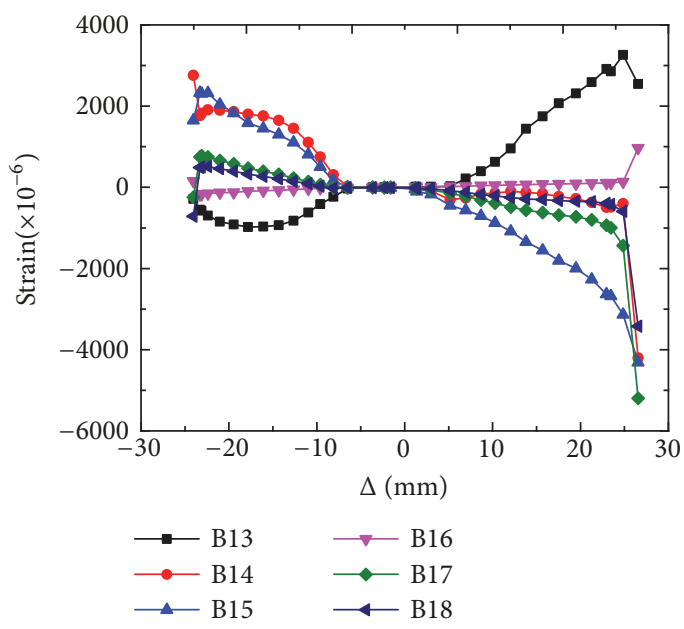

(c)

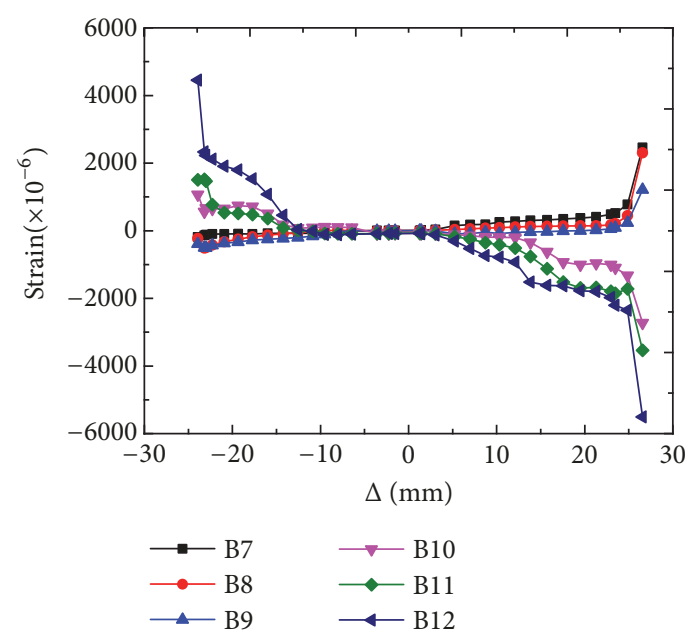

(b)

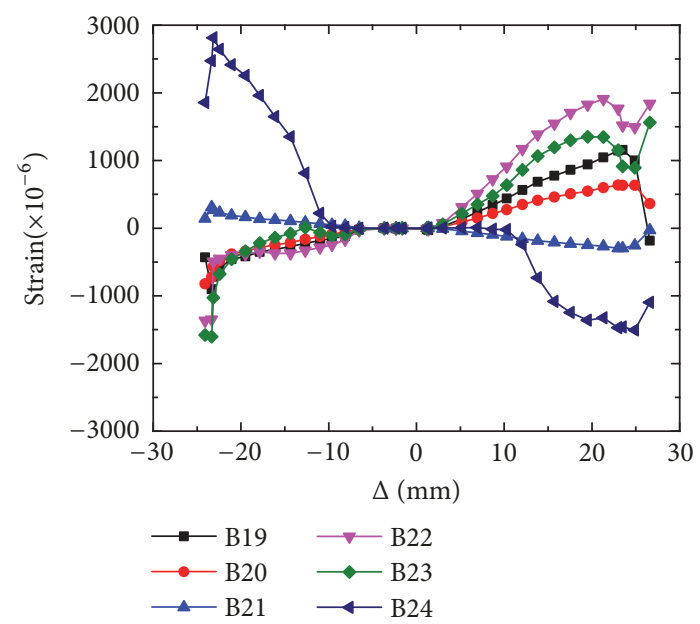

(d)

Figure 17: Strain of specimen T2. (a) Flank of web member. (b) Top chord. (c) The part of ribbed stiffener near the top chord. (d) The part of ribbed stiffener near the bottom chord.

(1) The force performance of the vertical rod connection is achieved by adopting the self-designed loading system, which can truly reflect the mechanical performance and deformation characteristics of the vertical rod shear connection under the action of alternating load.

(2) The ductility of the material in the heat-affected zone deteriorates due to the stress concentration at the type A connection between the chord and the side wall of the vertical rod, as well as the heat input of the welding. Added with alternating load, the plastic strain in the heat-affected zone is accumulated, and the ductility is reduced. Therefore, a U-shaped fracture crack is formed on the outside of the heataffected zone of the chord web and the side wall of the vertical rod for specimen Tl.

(3) In the type B connection, the strain at the connection between the stiffener and the chord web is the largest, thereby yielding first. As the loading displacement increases, the joint between the chord web and the stiffening plate cracks and develops, eventually causing the stiffening plate to be buckled and undergo structural damage.

(4) When the main design parameters are the same, the stiffness of type B connection is approximately three times that of the type A connection, and the bearing capacity is approximately three times that of the type A connection.

(5) The yielding platform is long, and the stiffness is degraded slowly so that the energy can be absorbed and dissipated well due to the sufficient plasticity development of the Type A connection material. Energy consumption performance is remarkably better than that of the type B connection.

In summary, the two types of vertical rod connections investigated in this study exhibit good seismic performance and can meet the engineering design requirements. 


\section{Notation}

\begin{tabular}{|c|c|}
\hline$a:$ & Specimen length \\
\hline$a_{0}:$ & $\begin{array}{l}\text { Thickness of specimen ends for material } \\
\text { test }\end{array}$ \\
\hline$b_{0}:$ & $\begin{array}{l}\text { Working width of specimen ends for } \\
\text { material test }\end{array}$ \\
\hline$b_{\mathrm{c}}:$ & Web member width \\
\hline$b_{\mathrm{f}}:$ & Chord width \\
\hline$b_{\mathrm{g}}:$ & Cover-plate width \\
\hline$b_{t}:$ & Width of ribbed stiffener \\
\hline$C:$ & $\begin{array}{l}\text { Transition length of specimen ends for } \\
\text { material test }\end{array}$ \\
\hline$D:$ & Final damage of the specimen \\
\hline$D_{\mathrm{i}}:$ & Damage of specimen in each load cycle \\
\hline$D_{0}:$ & Width of specimen ends for material test \\
\hline$E:$ & Energy dissipation coefficient \\
\hline$E_{\mathrm{s}}:$ & Young's modulus \\
\hline$f_{\mathrm{u}}:$ & Ultimate strength of steel \\
\hline$f_{\mathrm{y}}:$ & Yield strength of steel \\
\hline$H:$ & Length of specimen ends for material test \\
\hline$h:$ & Overall height of specimen \\
\hline$h_{1}:$ & Chord height \\
\hline$h_{2}:$ & $\begin{array}{l}\text { Net distance between top chord and } \\
\text { bottom chord }\end{array}$ \\
\hline$h_{\mathrm{c}}:$ & $\begin{array}{l}\text { The distance between the top and bottom } \\
\text { chord centroid }\end{array}$ \\
\hline$K_{0}:$ & Stiffness of specimen \\
\hline$K_{\mathrm{i}}:$ & Stiffness of the specimen in i load cycles \\
\hline$K_{\mathrm{i}-1}:$ & Stiffness of the specimen in i- 1 load cycles \\
\hline$L_{0}:$ & $\begin{array}{l}\text { Working length of specimen ends for } \\
\text { material test }\end{array}$ \\
\hline$n:$ & $\begin{array}{l}\text { Total cycling number when the specimen } \\
\text { is loaded to failure }\end{array}$ \\
\hline$P:$ & Counter-force of loading point \\
\hline$P_{\mathrm{d}}:$ & Failure load of specimen \\
\hline$P_{\mathrm{u}}:$ & Ultimate load of specimen \\
\hline$P_{\mathrm{y}}:$ & Yield load of specimen \\
\hline$S_{(\widehat{A B C}+\widehat{C D A})}:$ & $\begin{array}{l}\text { The area surrounded by the hysteresis } \\
\text { curve }\end{array}$ \\
\hline$S_{(\widehat{O B E}+O D F)}:$ & $\begin{array}{l}\text { The area of the triangle OBE and the } \\
\text { triangle ODF }\end{array}$ \\
\hline$t_{\mathrm{c}}:$ & Pip thickness of web member \\
\hline$t_{\mathrm{f}}:$ & Chord flange thickness \\
\hline$t_{\mathrm{g}}:$ & Cover-plate thickness \\
\hline$t_{\mathrm{t}}:$ & Thickness of ribbed stiffener \\
\hline$t_{\mathrm{w}}:$ & Chord web thickness \\
\hline$\Delta:$ & Displacement of loading point \\
\hline$\Delta_{\mathrm{d}}:$ & Damage displacement of specimen \\
\hline$\Delta_{\mathrm{u}}:$ & Ultimate displacement of specimen \\
\hline$\Delta_{\mathrm{y}}:$ & Yield displacement of specimen \\
\hline$\Delta K_{\mathrm{i}}:$ & $\begin{array}{l}\text { Stiffness degradation value of the } \\
\text { specimen in each load cycle }\end{array}$ \\
\hline$\zeta_{e q}:$ & Equivalent viscous damping coefficient \\
\hline$\mu:$ & Ductility coefficient. \\
\hline
\end{tabular}

\section{Data Availability}

The data used to support the findings of this study are available from the corresponding author upon request.

\section{Conflicts of Interest}

The authors declare that they have no conflicts of interest.

\section{Acknowledgments}

The authors would like to thank the National Natural Science Foundation of China (51568012), for financially supporting this research.

\section{References}

[1] K. J. Ma, H. G. Zhang, and T. Zheng, "Theory and practice of new type architectural space gridding structures," China Communications Press, 2006.

[2] J. S. Xu and L. H. Xue, "Modern prestressed concrete floor structure," China Architecture \& Building Press, 2013.

[3] Z. Chen, G. Wu, D. Feng, and K. Ma, "Numerical study of the static and dynamic characteristics of reinforced concrete cassette structures for high-rise buildings," The Structural Design of Tall and Special Buildings, vol. 28, no. 3, pp. 1-24, 2019.

[4] L. Jiang, K. J. Ma, and H. G. Zhang, "The dynamic property and comfort degree study on the steel-concrete composite vierendeel sandwich plate," Earthquake Engineering and Engineering Dynamics, vol. 37, no. 6, pp. 122-131, 2017.

[5] H. Luan, K. Ma, Y. Qin, X. Li, and Z. Chen, "Investigation on structural behavior of an innovative orthogonal-diagonal steel open-web sandwich floor system," Advances in Structural Engineering, vol. 19, no. 2, pp. 353-371, 2016.

[6] H. Luan, K. Ma, Y. Qin, Z. Chen, and Y. Wei, "Investigation of the structural behavior of an innovative steel open-web floor system," International Journal of Steel Structures, vol. 17, no. 4, pp. 1365-1378, 2017.

[7] Q. Chen, J. C. Xiao, K. J. Ma, and Z. C. Huang, "Effects of shear connector joints on static behavior in steel open-web sandwich plates," Journal of Guangxi University, vol. 43, no. 1, pp. 41-49, 2018 (Chinese).

[8] Z. Q. Bai, X. D. Liu, D. Xing, Y. H. Wei, and K. J. Ma, "Experimental research on mechanics characteristics for shear block of steel tube with t-section steel ribs," Industrial Construction, vol. 48, no. 1, pp. 159-164, 2018.

[9] C. C. Chen, S. W. Chen, M. D. Chung, and M. C. Lin, "Cyclic behaviour of unreinforced and rib-reinforced moment connections," Journal of Constructional Steel Research, vol. 61, no. 1, pp. 1-21, 2005.

[10] C.-C. Chen, C.-C. Lin, and C.-H. Lin, "Ductile moment connections used in steel column-tree moment-resisting frames," Journal of Constructional Steel Research, vol. 62, no. 8, pp. 793801, 2006.

[11] H. S. Park, D. C. Lee, B. K. Oh et al., "Performance-based multiobjective optimal seismic retrofit method for a steel momentresisting frame considering the life-cycle cost," Mathematical Problems in Engineering, vol. 2014, Article ID 305737, 14 pages, 2014.

[12] D. Sosa, D. Arévalo, E. D. Mora et al., "Experimental and analytical study of slender reinforced concrete shear wall under cyclic in-plane lateral load," Mathematical Problems in Engineering, vol. 2017, Article ID 4020563, 14 pages, 2017.

[13] L. Hu, Theoretical Analysis and Experimental Study on Semi Assembled Composite Open-Web Sandwich Plate Outsourcing 
U Type Steel Plate [Unpublished PhD Dissertation], Hunan University, 2017.

[14] L. Jiang, K. J. Ma, H. G. Zhang, and L. Li, “The design method of steel Vierendeel beam with shear connection," Xian University of Architecture \& Technology (Natural Science Edition), vol. 50, no. 3, pp. 354-360, 2018.

[15] JGJ 101-2015, Specification of Testing Methods for Earthquake Resistant Building, Chinese Building Industry Press, 2015.

[16] Z. L. Li, C. T. Zhang, W. L. Fan et al., "Experimental research on seismic behavior of a new type of thin-walled square steel tube beam-column connection," Engineering Mechanics, vol. 30, no. 2, pp. 72-81, 2013.

[17] G. Ballio and F. M. Mazzolani, Theory and Design of Steel Structures, Chapman and Hall, London, UK, 1983.

[18] S. Banno, I. H. P. Mamaghani, T. Usami, and E. Mizuno, "Cyclic elastoplastic large deflection analysis of thin steel plates," Journal of Engineering Mechanics, vol. 124, no. 4, pp. 363-370, 1998.

[19] I. H. P. Mamaghani, T. Usami, and E. Mizuno, "Inelastic large deflection analysis of structural steel members under cyclic loading," Engineering Structures, vol. 18, no. 9, pp. 659-668, 1996.

[20] G. L Bai, J. Q. Zhao, N. J. Du, B. Xie, and H. Gao, "Experimental study on seismic behavior of SRC abnormal interior joints and design advice," Journal of Building Structures, vol. 39, no. 7, pp. 33-45, 2018.

[21] W. B. Krätzig and Y. S. Petryna, "Quasistatic seismic damage indicators for rc structures from dissipating energies in tangential subspaces," Mathematical Problems in Engineering, vol. 2014, Article ID 615792, 11 pages, 2014. 


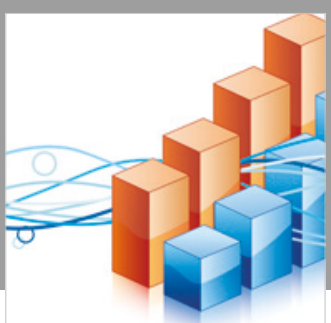

Advances in

Operations Research

\section{-n-m}
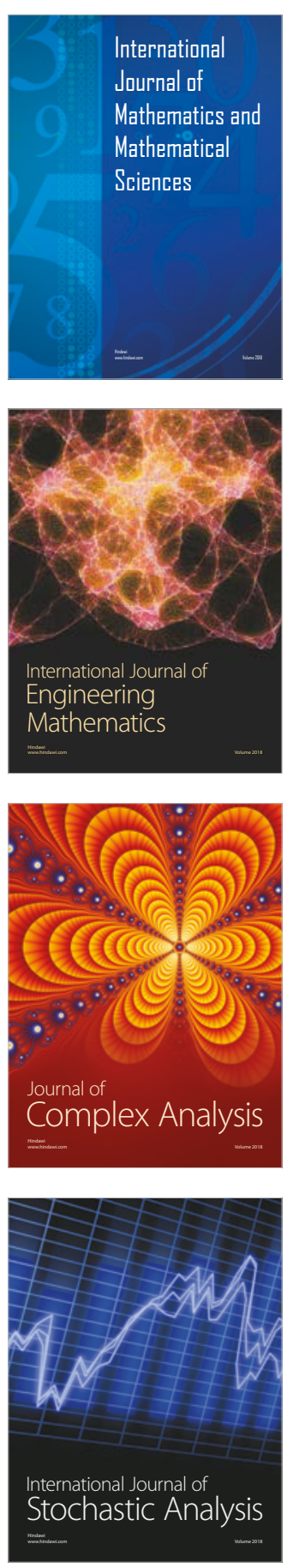
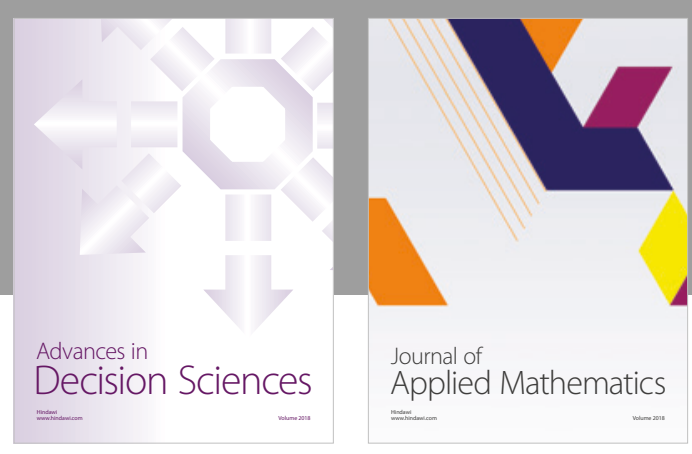

Journal of

Applied Mathematics
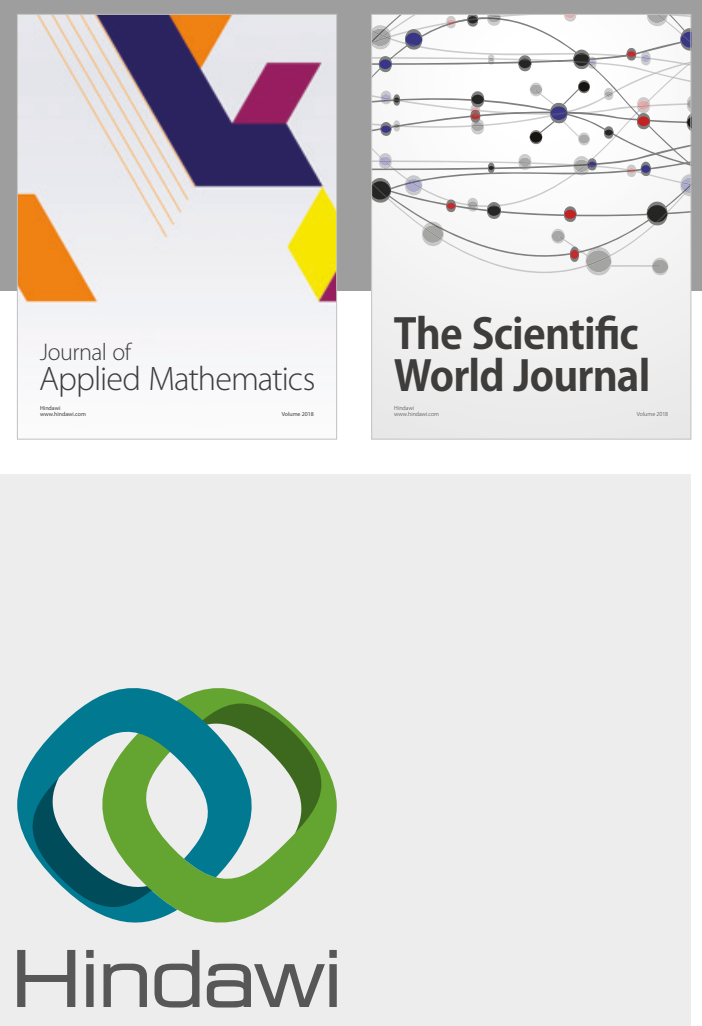

Submit your manuscripts at

www.hindawi.com

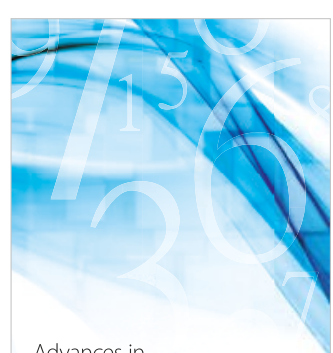

Advances in
Numerical Analysis
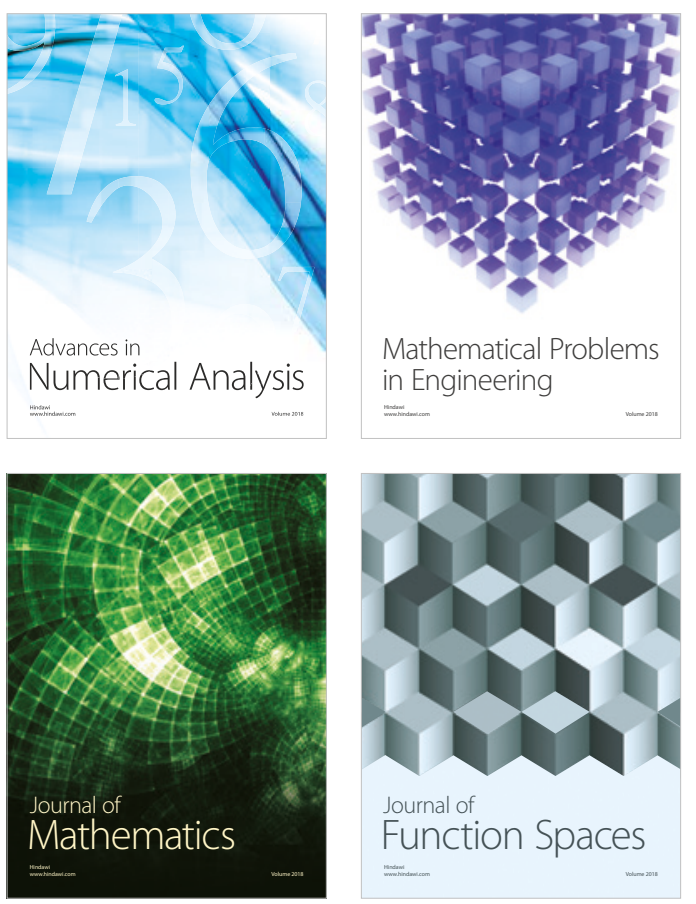

Mathematical Problems in Engineering

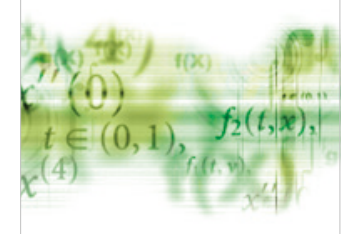

International Journal of

Differential Equations

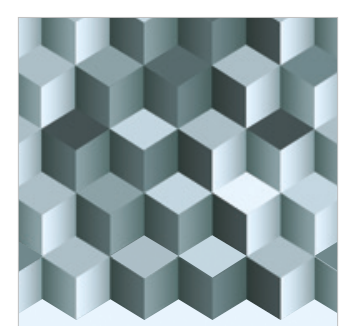

Journal of

Function Spaces

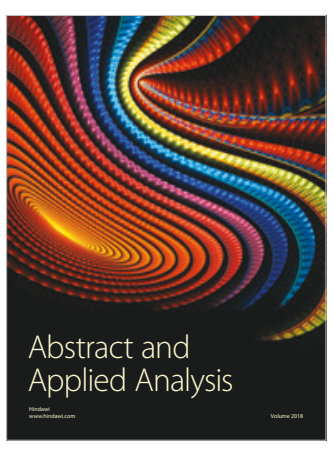

The Scientific

World Journal

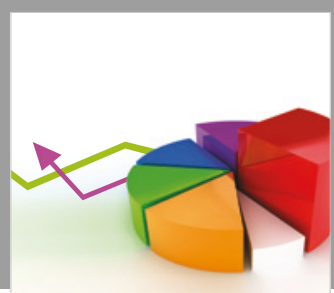

Journal of

Probability and Statistics
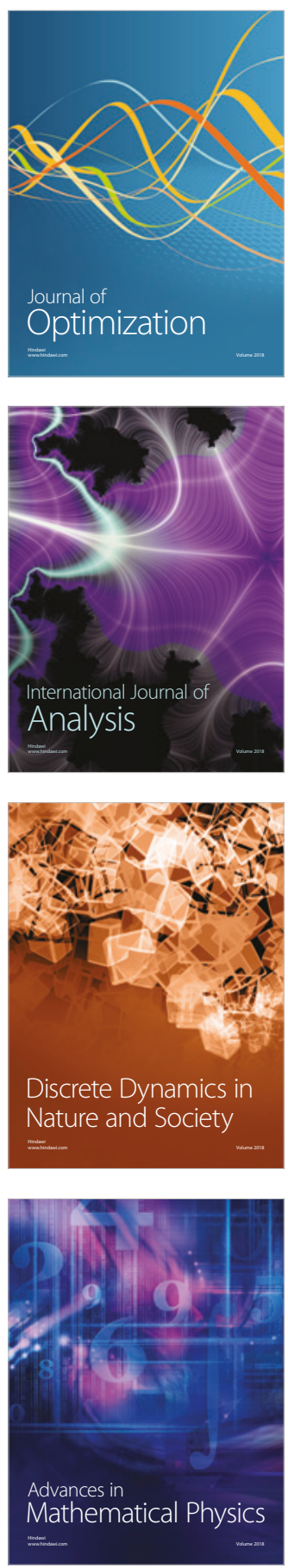